\title{
Emerging uses for pediatric hematopoietic stem cells
}

\author{
Jos Domen ${ }^{1}$, Kimberly Gandy ${ }^{1}$ and Jignesh Dalal ${ }^{2}$
}

Many new therapies are emerging that use hematopoietic stem and progenitor cells. In this review, we focus on five promising emerging trends that are altering stem cell usage in pediatrics: (i) The use of hematopoietic stem cell (HSC) transplantation, autologous or allogeneic, in the treatment of autoimmune disorders is one. (ii) The use of cord blood transplantation in patients with inherited metabolic disorders such as Hurler syndrome shows great benefit, even more so than replacement enzyme therapy. (iii) Experience with the delivery of gene therapy through stem cells is increasing, redefining the potential and limitations of this therapy. (iv) It has recently been shown that human immunodeficiency virus (HIV) infection can be cured by the use of selected stem cells. (v) Finally, it has long been postulated that HSC-transplantation can be used to induce tolerance in solid-organ transplant recipients. A new approach to tolerance induction using myeloid progenitor cells will be described.

T he use of stem cells to repair or replace tissues has become the focus of intense investigation over the past $15 \mathrm{y}$. The identification of pluripotent stem cells, and, more recently, induced pluripotent stem cells or IPS cells, has created high expectations. Although these and other stem cell populations undoubtedly have great potential, many obstacles remain in the path of routine clinical use. This review will focus on hematopoietic stem cells (HSCs), cells that have been frequently used in the clinical setting since the early 1970s, typically from sources such as bone marrow, mobilized peripheral blood, or cord blood. Although these cells are more limited in their developmental potential than pluripotent cells, new clinical uses continue to emerge. HSCs have been used extensively in oncological settings, as they allow for more intensive chemotherapeutic regimens and additionally provide replacement of the affected tissue in blood-borne disorders such as leukemias and lymphomas. The potential for additional use of HSCs has long been recognized but has been hampered by the morbidity and mortality associated with HSC transplantation. Procedural improvements over the years have expanded the use of HSCs to the treatment of other diseases, and current estimates are that at many centers as much as a third of all pediatric hematopoietic cell transplantations (HCTs) are for nonmalignant disease (1). These improvements include the development of successful reduced-intensity preconditioning regimens, the ability to match donors at multiple loci, and for pediatric use the availability of precharacterized units of cord blood. In this review, we will describe some of these emerging indications that have entered clinical use as well as several that have not yet moved beyond the experimental stage.

Before discussing the emerging uses, it is important to say a few words about nomenclature. Cells for an HCT can have several origins: bone marrow, mobilized peripheral blood, or umbilical cord blood (UCB). The tissue or cells can also be processed in different ways. The whole tissue can be used or it may be enriched for certain cells. For instance, populations can be enriched for $\mathrm{CD} 34^{+}$cells by positive selection with CD34-selecting devices or populations can be more rigorously purified using combinations of two or more markers. $\mathrm{CD}^{+} 4^{+}, \mathrm{CD} 0^{+}, \mathrm{CD}_{3} 8^{-}, \mathrm{CD}_{4} 4 \mathrm{RA}^{-}$are examples of markers for human HSCs (2). Although terms are often used interchangeably, these distinctions are important, as these preparations have different properties and outcomes. In this review, we reserve the use of HSC transplantation (HSCT) for transplantations of purified HSCs without contaminating lymphocytes or other cells.

\section{AUTOIMMUNE DISEASES}

Autoimmune diseases, including juvenile idiopathic arthritis, systemic lupus erythematosus and others affect $\sim 3-5 \%$ of the general population (3) and are a major cause of morbidity in children (4). There is a clear need for new treatment modalities. The underlying process in autoimmune diseases is the recognition, and destruction, of specific tissues by the immune system. In principle, this can be treated by eradicating the immune system and replacing it with either a different or a newly generated immune system. Initial studies have indicated that HCT, performed to treat malignant diseases, could indeed cure autoimmune diseases. However, efforts to date to establish this in pediatric patients have been limited, for some of the same reasons that have limited their application in adult autoimmune patients. Foremost is the morbidity and mortality associated with HCT. Even though severe autoimmune diseases also carry a significant mortality risk (5), this tends to be long term, whereas the $2-4 \%$ treatmentrelated mortality for HCT (6) increases the short-term 


\section{Review | Domen et al.}

mortality. In addition, there are continuing questions as to the choice of cells: autologous versus allogeneic. The use of autologous cells has fewer complications, but as the stem cells in these grafts carry the original predisposition to the development of autoreactive immune cells, the treatment may not result in a long-term cure. For example, in a mouse model of autoimmune diabetes mellitus, there is no evidence of improved long-term survival following transplantation with autologous HSC. Clinical results are variable $(4,7)$. In the absence of environmental factors that trigger the initial autoimmune response, long-lived remissions of the disease can be achieved. Also, there may be qualitative changes in the reconstituted immune repertoire that diminish susceptibility to relapse (7). In other cases relapses follow the initial remission. An interesting variant of autologous HCT, i.e., resetting of the autoreactive immune system, was recently reported in a patient with refractory juvenile polymyositis. Two rounds, 13 and $10 \mathrm{~d}$, of anti-CD52 treatment (alemtuzumab) resulted in transient immune ablation. Clinical symptoms improved significantly over the following several months and have been stable for more than $6 \mathrm{y}$ to date (8).

To remove the underlying susceptibility to the disease, the transplanted HSCs should be allogeneic. Another option, in principle at least, is autologous HSCs combined with gene therapy. This assumes that the underlying cause is known at the gene level, something that will increasingly be the case with the advent in sequencing technology (9). Further trials are clearly needed to test both autologous and allogeneic HCT. This is underscored by the fact that relapses have been reported, even after successful allogenic HCT (10). Despite the obvious potential, major hurdles remain, such as access to insurance (7). Even if long-term outcome is better than with conventional treatments (immunosuppressants and low-dose chemotherapy), it will be important to reduce early mortality associated with HCT to increase interest in trials. In addition, the continuous development of new biologic agents such as costimulation blockers, cytokine inhibitors, and others $(11,12)$ and the trials they require also limits the pool of patients that are available for HCT trials after they have failed conventional therapy.

In addition to these "classical" autoimmune diseases, there are "pre-existing" autoimmune-like diseases that are observed following organ transplantation, specifically the presence of antibodies that recognize the incoming organ (panel-reactive antibodies or PRAs) (13). These are especially problematic if they are complement fixing (14). This is not strictly "auto"immune as the transplanted organ is allogeneic. However, after the transplantation, the organ will become an essential part of the body. Consequently, an immune response in this setting is similarly devastating, all the more so because the presence of recognized PRA can prevent a patient from receiving an urgently needed organ. Some of the solutions discussed earlier, specifically the use of HCT, may be applicable to these situations as well and could potentially be achieved as part of a tolerance-induction protocol as discussed in the section on tolerance induction.

\section{INHERITED METABOLIC DISORDERS}

Another area in which HCT can be curative is certain inherited metabolic and genetic disorders, such as Hurler syndrome, osteopetrosis, Gaucher disease, and others (15-19). Many of these are lysosomal or peroxisomal storage disorders. These diseases, caused by single gene defects, can have devastating consequences if left untreated. Severe forms of inherited metabolic disorders, such as Hurler syndrome, result in a progressive disease fatal in early childhood with psychomotor retardation, severe skeletal abnormalities, and life-threatening cardiac and pulmonary complications, in the case of Hurler syndrome because of lack of the lysosomal enzyme a-1-iduronidase and a resulting inability to break down glycosaminoglycans (16). Treatment options are limited for patients with inherited metabolic disorders. Enzyme replacement therapy has become available for a number of these disorders. Cells have the ability to take up enzyme provided externally. Although this can be very useful in the milder syndromes, enzyme replacement therapy is limited by the inability of the externally provided enzymes to cross the blood-brain barrier, and as such does not work for diseases with central nervous system involvement. As single gene disorders, these are obvious candidates for gene therapy $(15,20)$. However, the only current treatment option that can treat disorders with central nervous system involvement is HCT in the form of bone marrow or cord blood transplantation (16-18). In animal models, cells derived from human hematopoietic stem and progenitor cells can have widespread, nonhematopoietic tissue distribution (21). The engrafting cells remain hematopoietic $(22,23)$ and can be present in many tissues, including nervous tissue, in the form of microglial cells and tissue macrophages and can provide the enzyme to neighboring affected cells (18), a concept recognized in tissue culture experiments in the 1960s (24).

The original report on the successful use of HCT to treat a child with Hurler syndrome was published 30 y ago (25). Due to the severity of the underlying disease, more than 2,000 patients with severe forms of inherited metabolic diseases have been treated with HCT. Currently, the preferred source of the HCT is usually UCB. UCB as a source has several advantages. Due to increased inventory, and more human leucocyte antigen permissible mismatches, a match can almost always be found rapidly, important in this disease where rapid treatment leads to better outcome. UCB has been found to lead to both better engraftment and higher enzyme levels in inherited metabolic disorder patients as compared with HCT with cells derived from bone marrow $(16,18,26,27)$. Overall, improvement can be quite significant, and in a single center report with follow-up of 3-20 y, more than $85 \%$ of parents reported quality of life of their children after HCT as good to excellent. Although developmentally delayed, almost $80 \%$ of these children attend regular school (19).

HCT can be combined with enzyme replacement therapy if improvement is limited or complications arise late after HCT. Significant improvements in lung disease have been seen with enzyme replacement therapy as late as $12 \mathrm{y}$ post-HCT, in the presence of continuing high-level donor 
chimerism (28). One area that seems mostly unresponsive to HCT in metabolic disorders is that of the associated musculoskeletal disorders, which can be severe and disabling. In Hurler syndrome, these include odontoid hypoplasia, thoracolumbar kyphosis, genu valgum, hip dysplasia, and carpal tunnel syndrome (29). Early recognition and surgical intervention are important to optimize quality of life. Addition of mesenchymal stem cells (reviewed elsewhere in this issue) to the HCT may be one treatment option that has the potential to help improve long-term musculoskeletal development in these children $(30,31)$.

\section{GENE THERAPY}

Gene therapy has been studied as a means of addressing mostly single gene disorders for more than four decades, going through more than 1,000 clinical trials, ongoing or completed (32). The field has experienced many ups and downs but continues to develop and continues to hold great promise (33). Although the majority of trials have been aimed at cancer, other diseases such as primary immunodeficiencies have been studied as well (34). Additional diseases, like autoimmune diseases (35) and inherited metabolic disorders (15) are also in principle open to this treatment option, although with various limitations. One limitation for severe inherited metabolic diseases is the fact that the time to effective treatment needs to be as short as possible $(17,18)$.

The possible approaches to gene therapy have increased dramatically. Initial work was heavily focused on vector development necessary to introduce, and correctly express, a copy of the gene of interest into cells. For obvious reasons, this work has focused on viral vectors, including retroviruses, lentiviruses, adenoviral vectors and others, all with different strengths and weaknesses, the discussion of which falls outside of the context of this review $(33,36)$. As one example, some of the inherent risks were revealed in the insertional mutagenesis (activating the LMO2 gene), and resulting T-cell leukemias, in severe combined immunodeficiency (SCID) patients participating in gene therapy trials with retroviral vectors $(37,38)$. Safer vectors continue to be developed and constructed, but the associated risks cannot be fully appreciated until they are used in clinical trials, with a significant follow-up (34).

In addition to the introduction of genes combined with control regions, and the ability to replace genes through homologous recombination, it is now also becoming possible to edit the genome using engineered zinc-finger nucleases (39), or even oligonucleotides (40). These approaches, which are currently under development, allow for subtle modifications while retaining the normal expression pattern of the repaired gene. Gene knockdown, through homologous recombination (mostly animal models) or RNAi can be another target of gene therapy (33).

Gene therapy is usually undertaken during in vitro manipulations of target cells, which, after selection, have to be reintroduced into the patient. The manipulated cells can be mature effector cells such as T cells (41). Alternatively, they can be stem cells that will repopulate organ systems. Although other stem cells are increasingly targeted, HSCs have been a favorite for gene therapy due to the fact that they are well characterized and that clinical transplantation protocols are used routinely (42). Gene therapy is a form of cellular therapy, in the sense that the engineered or repaired cells need to be reintroduced into the patient.

Overall gene therapy may become more and more interesting as techniques continue to improve. Of note, the rapidly falling costs of whole-genome sequencing have opened up the possibility of employing routine genome or exome testing during normal screening. This will greatly facilitate the recognition of targets for gene therapy, especially targets for genome editing (9).

\section{HIV INFECTION}

Combination antiretroviral therapy has greatly reduced morbidity and mortality associated with HIV infections. This therapy, however, does not cure the disease but effectively controls it (43). To achieve a cure, either the virus needs to remain present at stable, low levels without further treatment (functional cure) or the virus needs to be eradicated (sterilizing cure). The potential for functional cures can be seen in what are called "elite controllers." Here, however, we want to discuss the HIV eradication that was achieved after a bone marrow transplantation, the only such case reported to date (44-46). The bone marrow transplanted into a German patient with a relapse of acute myelogenous leukemia (AML) was derived from a CCR $5 \Delta 32 /$ $\Delta 32$ donor. Bone marrow from the same donor was retransplanted 13 mo later after a second AML relapse. The patient stopped treatments with combined antiretroviral therapy and remains free of any evidence of HIV infection $3.5 \mathrm{y}$ later. It is still unclear at the moment how the virus was eradicated, especially from the long-lived reservoirs. The donor CD4 cells, which lack surface expression of CCR5, remain susceptible to CXCR4-tropic HIV in vitro.

This single case, obviously, does not indicate a clinical treatment option that can be readily adapted to other patients. It does, however, indicate that there is potential benefit in this approach. Further studies are essential to better understand the mechanisms involved to be able to predict the outcome of transplantations. Combined antiretroviral therapy has been greatly improved over the years, and in many cases bone marrow transplantation, with its associated morbidity and mortality, should not be considered, even were a better understanding of the phenomenon observed in this patient to be obtained. However, as successful as combined antiretroviral therapy has become, it remains associated with significant morbidity and reduced life span. Therefore, especially in pediatric patients with a long remaining life span, more drastic treatment options may be acceptable, assuming they would lead to a cure of the disease.

Mostly, this case is a reminder that the treatment possibilities presented by HCT are much broader than currently appreciated, and clinical use may well widen significantly in the future. 


\section{TOLERANCE INDUCTION}

In large part due to the development of immunosuppressive drugs, organ transplantation has become an effective therapy for the treatment of end-stage organ disease. Longterm graft and patient survival, however, continue to be limited. Despite advances in immunosuppressants, most grafts eventually succumb to rejection. Only $40-60 \%$ of the most successful graft types, especially heart and liver, continue to function at $10 \mathrm{y}$. For others, like lung, 10-y graft survival can be as low as $20 \%$ (47). In addition, the need for continued immunosuppression leads to many, potentially lethal, complications.

Transplantation tolerance is a phenomenon defined as the lack of destructive immunological activity to a foreign graft in an otherwise immunocompetent host. Achieving tolerance means that the life span of the transplanted organ will be extended. It also abolishes the need for immunosuppressants and the accompanying side effects. For the past $50 \mathrm{y}$, clinical implementation has been an elusive goal, largely due to the complexity and redundancy of the immune system. Multiple methods of tolerance induction have been proposed (48-51). There are incidental reports of patients who were removed from immunosuppressants without detectable damage to their transplant grafts (52-55). Some of these patients have eventually lost their grafts or been found to be undergoing rejection. It is difficult to determine parameters that predict long-term tolerance (56). Hematopoietic microchimerism (57), or even full conversion (58), can play an important role. Other approaches to clinical tolerance induction include costimulatory blockades, blocking $\mathrm{T}$ cell receptors such as CD28-CD80/86 or CD154-CD40 to induce anergy rather than activation $(59,60)$. These may be more efficient in maintenance than primary induction. Peripheral T-cell depletion with antibodies, such as alemtuzumab (antiCD52), can result in severe T-cell depletion but typically does not result in tolerance (60-63). The most reproducible method appears to be hematopoietic reconstitution. In this method, blood cells from the organ donor are infused into a genetically disparate recipient (allogeneic HCT) and the recipient's blood system is reconstituted in large part with donor blood cells. The effectiveness of this method may result from the fact that hematopoietic reconstitution addresses a variety of central and peripheral tolerance induction mechanisms and thus the redundancy in the system $(48,49,64)$.

\section{TOLERANCE THROUGH CELLULAR THERAPY}

Tolerance induction through hematopoietic infusion can be achieved using various types of hematopoietic cell grafts, including rigorously purified HSCs (65). Tolerance is dependent on donor-specific hematopoietic engraftment, which is affected by many variables, including cell dose and type(s), level of mismatching, and pre- and postconditioning. Two of the ongoing approaches include the use of total lymphoid irradiation (TLI) and mixed chimerism (51). Samuel Strober has persistently sought tolerance induction with the use of TLI and lymphocyte infusion (66-70). There have been several clinical reports from his group. One of these reports discusses three patients that have become tolerant with this preconditioning regimen $(54,71)$. Another report describes four patients, two of which were withdrawn from immunosuppression but experienced treatable rejection episodes (72). A third describes a patient who has been off immunosuppression for more than 28 mo (73).

The laboratory of David Sachs has long been in pursuit of tolerance through infusion of hematopoietic cells $(74,75)$. This laboratory moved to sublethal preconditioning regimens as it appeared that full hematopoietic chimeras would be immunoincompetent. They pursued a systematic line of experimentation (76-79), eventually resulting in clinical trials (80-83). The results in human leucocyte antigen identical transplantation were promising. This led to a progression toward haploidentical transplantation. The most recent trial of five patients tested bone marrow and kidney transplantation without underlying malignancy. Despite transient donor engraftment, tolerance (the ability to withdraw immunosuppression) was observed in four of the patients (83).

Use of hematopoietic reconstitution for tolerance induction has been limited by the attendant morbidity and mortality. One serious problem is the initial neutropenia and immunoincompetence, which leaves the recipient vulnerable. Recently, a population of cells known as myeloid progenitors (MPs) has been identified by cell-surface markers $(84,85)$. MPs are progeny of HSCs with the potential to give rise to myeloid, erythroid, and granulocytic cells of the blood system. Infusion of these cells in neutropenic hosts has been shown to provide transient resistance to fungal and bacterial pathogens in a nonmajor histocompatibility complexdependent fashion $(86,87)$. A recent study in an animal model indicates that MPs can be added to allogeneic HSC grafts without affecting tolerance induction (88). In fact, in this model strong MP-specific tolerance is observed without the need for significant long-term multilineage engraftment by MP-derived cells. Characterization of the animals suggests that regulatory $\mathrm{T}$ cells may be involved in either inducing or maintaining tolerance.

\section{CONCLUSIONS}

In this overview, we have listed several emerging uses for HSCs in children, mostly in the form of bone marrow, mobilized peripheral blood or UCB transplantation. Some of these uses are just starting to emerge whereas others are much closer to routine clinical practice. However, all of these emerging uses have factors in common. Most importantly, continuation of the reduction in morbidity and mortality associated with HCT that has been observed (89) would greatly facilitate both trials and acceptance in clinical practice. The current need to weigh long-term gain against short-term mortality is not conducive to wider acceptance.

Over the years, the complications associated with HCT have been addressed in various ways. The development of reducedintensity conditioning regimens, or mini-transplants, has greatly reduced the complications associated with the original 
lethal preconditioning. Graft-versus-host disease is a doubleedged sword in HCTs undertaken in patients with malignant disease and clearly a major hurdle in emerging uses as discussed here. Graft-versus-host disease can be avoided altogether by the use of purified HSCs, although higher doses may be necessary to ensure engraftment. Facilitator cells could be developed for this purpose as well $(90,91)$.

Ongoing improvements include the development of adjuvants for HCT, especially those aimed at reducing infectious complications. Myeloid progenitor cells have been shown to be of special interest in this respect because they can be cryopreserved, used independent of major histocompatibility complex matching, and provide rapid and mostly transient engraftment that provides protection against bacterial and fungal pathogens $(86,87,92)$.

Additional improvements in conditioning regimens to further reduce the toxicity associated with HCT will be important. For example, preclinical studies have indicated that it may be possible to develop a preconditioning regimen using only monoclonal antibodies rather than chemotherapeutics or irradiation. The basis for this observation is the realization that HSCs are dependent on two survival signals, one involving the BCL-2 pathway and the other initiated by c-Kit/KitL signaling (93). The lack of either pathway results in apoptosis. Using this information, Irving Weissman's group at Stanford University has demonstrated that blocking antibodies to c-Kit can be used to eliminate HSCs from mice and will precondition the mice for HSCT (94). This approach, using a monoclonal or small molecule, could be combined with depleting antibodies directed against $\mathrm{T}$ cells and natural killer cells as well as B cells, many of which exist and some of which, like anti-CD52/alemtuzumab, are in widespread clinical use $(95,96)$. Combined, this could result in a targeted approach with limited toxicity. Blocking antibodies against c-Kit not only affect HSCs in mice but also result in skin color changes and male sterility, both of which reverse on discontinuation $(94,97,98)$.

Finally, if the promises encapsulated in gene therapy begin to bear fruit, this may also help as it will allow for the replacement of allogeneic HCTs by repaired autologous HCTs for specific diseases, something that should reduce the HCT-related complications.

\section{ACKNOWLEDGMENTS}

The authors thank Jennifer Marshall for critical reading of the manuscript.

\section{STATEMENT OF FINANCIAL SUPPORT}

J.D. and K.G. are supported by grants from the Thoracic Surgery Foundation for Research and Education and Advancing Healthier Wisconsin.

Disclosure: The authors report no conflict of interest.

\section{REFERENCES}

1. Pulsipher MA, Horwitz EM, Haight AE, et al. Advancement of pediatric blood and marrow transplantation research in North America: priorities of the Pediatric Blood and Marrow Transplant Consortium. Biol Blood Marrow Transplant 2010;16:1212-21.

2. Czechowicz A, Weissman IL. Purified hematopoietic stem cell transplantation: the next generation of blood and immune replacement. Immunol Allergy Clin North Am 2010;30:159-71.
3. Rabusin M, Andolina M, Maximova N; EBMT Paediatric, Autoimmune Diseases Working Parties. Haematopoietic SCT in autoimmune diseases in children: rationale and new perspectives. Bone Marrow Transplant 2008;41:Suppl 2:S96-9.

4. Krauss AC, Kamani NR. Hematopoietic stem cell transplantation for pediatric autoimmune disease: where we stand and where we need to go. Bone Marrow Transplant 2009;44:137-43.

5. Bernatsky S, Boivin JF, Joseph L, et al. Mortality in systemic lupus erythematosus. Arthritis Rheum 2006;54:2550-7.

6. Dvorak CC, Agarwal R, Dahl GV, Gregory JJ, Feusner JH. Hematopoietic stem cell transplant for pediatric acute promyelocytic leukemia. Biol Blood Marrow Transplant 2008;14:824-30.

7. Sullivan KM, Muraro P, Tyndall A. Hematopoietic cell transplantation for autoimmune disease: updates from Europe and the United States. Biol Blood Marrow Transplant 2010;16:S48-56.

8. Reiff A, Shaham B, Weinberg KI, Crooks GM, Parkman R. Anti-CD52 antibody-mediated immune ablation with autologous immune recovery for the treatment of refractory juvenile polymyositis. J Clin Immunol 2011;31:615-22.

9. Cooper GM, Shendure J. Needles in stacks of needles: finding disease-causal variants in a wealth of genomic data. Nat Rev Genet 2011;12:628-40.

10. Marmont AM, Gualandi F, Occhini D, et al. Catastrophic relapse of Evans syndrome five years after allogeneic BMT notwithstanding full donor chimerism. Terminal hemolytic-uremic syndrome. Autoimmunity 2006;39:505-11.

11. Moss KE, Isenberg DA. Comparison of renal disease severity and outcome in patients with primary antiphospholipid syndrome, antiphospholipid syndrome secondary to systemic lupus erythematosus (SLE) and SLE alone. Rheumatology (Oxford) 2001;40:863-7.

12. Martini G, Foeldvari I, Russo R, et al.; Juvenile Scleroderma Working Group of the Pediatric Rheumatology European Society. Systemic sclerosis in childhood: clinical and immunologic features of 153 patients in an international database. Arthritis Rheum 2006;54:3971-8.

13. Hooper DK, Hawkins JA, Fuller TC, Profaizer T, Shaddy RE. Panel-reactive antibodies late after allograft implantation in children. Ann Thorac Surg 2005;79:641-4; discussion 645.

14. Chin C, Chen G, Sequeria F, et al. Clinical usefulness of a novel C1q assay to detect immunoglobulin $\mathrm{G}$ antibodies capable of fixing complement in sensitized pediatric heart transplant patients. J Heart Lung Transplant 2011;30:158-63.

15. Nakamura K, Hattori K, Endo F. Newborn screening for lysosomal storage disorders. Am J Med Genet C Semin Med Genet 2011;157:63-71.

16. Boelens JJ, Rocha V, Aldenhoven $M$, et al.; EUROCORD, Inborn error Working Party of EBMT and Duke University. Risk factor analysis of outcomes after unrelated cord blood transplantation in patients with hurler syndrome. Biol Blood Marrow Transplant 2009;15:618-25.

17. Prasad VK, Kurtzberg J. Cord blood and bone marrow transplantation in inherited metabolic diseases: scientific basis, current status and future directions. Br J Haematol 2010;148:356-72.

18. Prasad VK, Kurtzberg J. Transplant outcomes in mucopolysaccharidoses. Semin Hematol 2010;47:59-69.

19. Gassas A, Raiman J, White L, et al. Long-term adaptive functioning outcomes of children with inherited metabolic and genetic diseases treated with hematopoietic stem cell transplantation in a single large pediatric center: parents' perspective. J Pediatr Hematol Oncol 2011;33:216-20.

20. Cartier N, Aubourg P. Hematopoietic stem cell gene therapy in Hurler syndrome, globoid cell leukodystrophy, metachromatic leukodystrophy and X-adrenoleukodystrophy. Curr Opin Mol Ther 2008;10:471-8.

21. Hess DA, Craft TP, Wirthlin L, et al. Widespread nonhematopoietic tissue distribution by transplanted human progenitor cells with high aldehyde dehydrogenase activity. Stem Cells 2008;26:611-20.

22. Wagers AJ, Sherwood RI, Christensen JL, Weissman IL. Little evidence for developmental plasticity of adult hematopoietic stem cells. Science 2002;297:2256-9.

23. Massengale $M$, Wagers AJ, Vogel H, Weissman IL. Hematopoietic cells maintain hematopoietic fates upon entering the brain. J Exp Med 2005;201:1579-89. 
24. Fratantoni JC, Hall CW, Neufeld EF. Hurler and Hunter syndromes: mutual correction of the defect in cultured fibroblasts. Science 1968;162:570-2.

25. Hobbs JR, Hugh-Jones K, Barrett AJ, et al. Reversal of clinical features of Hurler's disease and biochemical improvement after treatment by bonemarrow transplantation. Lancet 1981;2:709-12.

26. Peters C, Shapiro EG, Anderson J, et al. Hurler syndrome: II. Outcome of HLA-genotypically identical sibling and HLA-haploidentical related donor bone marrow transplantation in fifty-four children. The Storage Disease Collaborative Study Group. Blood 1998;91:2601-8.

27. Escolar ML, Poe MD, Provenzale JM, et al. Transplantation of umbilical-cord blood in babies with infantile Krabbe's disease. N Engl J Med 2005;352:2069-81.

28. Valayannopoulos V, de Blic J, Mahlaoui N, et al. Laronidase for cardiopulmonary disease in Hurler syndrome 12 years after bone marrow transplantation. Pediatrics 2010;126:e1242-e1247.

29. van der Linden MH, Kruyt MC, Sakkers RJ, et al. Orthopaedic management of Hurler's disease after hematopoietic stem cell transplantation: a systematic review. J Inherit Metab Dis 2011;34:657-69.

30. Koç ON, Day J, Nieder M, et al. Allogeneic mesenchymal stem cell infusion for treatment of metachromatic leukodystrophy (MLD) and Hurler syndrome (MPS-IH). Bone Marrow Transplant 2002;30:215-22.

31. Ball LM, Bernardo ME, Locatelli F, Egeler RM. Potential role of mesenchymal stromal cells in pediatric hematopoietic SCT. Bone Marrow Transplant 2008;42:Suppl 2:S60-6.

32. Gillet JP, Macadangdang B, Fathke RL, Gottesman MM, Kimchi-Sarfaty C. The development of gene therapy: from monogenic recessive disorders to complex diseases such as cancer. Methods Mol Biol 2009;542:5-54.

33. Kay MA. State-of-the-art gene-based therapies: the road ahead. Nat Rev Genet 2011;12:316-28.

34. Fischer A, Hacein-Bey-Abina S, Cavazzana-Calvo M. Gene therapy for primary adaptive immune deficiencies. J Allergy Clin Immunol 2011;127:1356-9.

35. Alderuccio F, Nasa Z, Chung J, et al. Hematopoietic stem cell gene therapy as a treatment for autoimmune diseases. Mol Pharm 2011;8:1488-94.

36. Mingozzi F, High KA. Therapeutic in vivo gene transfer for genetic disease using AAV: progress and challenges. Nat Rev Genet 2011;12:341-55.

37. Hacein-Bey-Abina S, Garrigue A, Wang GP, et al. Insertional oncogenesis in 4 patients after retrovirus-mediated gene therapy of SCID-X1. J Clin Invest 2008;118:3132-42.

38. Howe SJ, Mansour MR, Schwarzwaelder K, et al. Insertional mutagenesis combined with acquired somatic mutations causes leukemogenesis following gene therapy of SCID-X1 patients. J Clin Invest 2008;118:3143-50.

39. Urnov FD, Rebar EJ, Holmes MC, Zhang HS, Gregory PD. Genome editing with engineered zinc finger nucleases. Nat Rev Genet 2010;11:636-46.

40. Aarts M, te Riele H. Progress and prospects: oligonucleotide-directed gene modification in mouse embryonic stem cells: a route to therapeutic application. Gene Ther 2011;18:213-9.

41. Brenner MK, Heslop HE. Adoptive T cell therapy of cancer. Curr Opin Immunol 2010;22:251-7.

42. Naldini L. Ex vivo gene transfer and correction for cell-based therapies. Nat Rev Genet 2011;12:301-15.

43. Lewin SR, Rouzioux C. HIV cure and eradication: how will we get from the laboratory to effective clinical trials? AIDS 2011;25:885-97.

44. Hütter G, Nowak D, Mossner M, et al. Long-term control of HIV by CCR 5 Delta32/Delta32 stem-cell transplantation. N Engl J Med 2009;360:692-8.

45. Hütter G, Schneider T, Thiel E. Transplantation of selected or transgenic blood stem cells - a future treatment for HIV/AIDS? J Int AIDS Soc 2009; $12: 10$

46. Allers K, Hütter G, Hofmann J, et al. Evidence for the cure of HIV infection by CCR $5 \Delta 32 / \Delta 32$ stem cell transplantation. Blood 2011;117:2791-9.

47. OPTN/SRTR Annual Report 1999-2008, 2009. (http://ustransplant.org/ annual_reports/current/ar_archives.htm.) Accessed 7 January 2011.

48. Gandy K, Domen J, Copeland J. Tolerance in heart transplantation: Current and future role. InWatson RR, Larson DF, eds. Immune Dysfunction and Immunotherapy in Heart Disease. Oxford, UK: Blackwell, 2007:195-206.

49. Sykes M. Hematopoietic cell transplantation for tolerance induction: animal models to clinical trials. Transplantation 2009;87:309-16.
50. Bishop GA, Ierino FL, Sharland AF, et al. Approaching the promise of operational tolerance in clinical transplantation. Transplantation 2011;91:1065-74.

51. Strober S, Spitzer TR, Lowsky R, Sykes M. Translational studies in hematopoietic cell transplantation: treatment of hematologic malignancies as a stepping stone to tolerance induction. Semin Immunol 2011;23:273-81.

52. Owens ML, Maxwell JG, Goodnight J, Wolcott MW. Discontinuance of immunosuprression in renal transplant patients. Arch Surg $1975 ; 110: 1450-1$.

53. Uehling DT, Hussey JL, Weinstein AB, Wank R, Bach FH. Cessation of immunosuppression after renal transplantation. Surgery 1976;79:278-82.

54. Strober S, Benike C, Krishnaswamy S, Engleman EG, Grumet FC. Clinical transplantation tolerance twelve years after prospective withdrawal of immunosuppressive drugs: studies of chimerism and anti-donor reactivity. Transplantation 2000;69:1549-54.

55. Zoller KM, Cho SI, Cohen JJ, Harrington JT. Cessation of immunosuppressive therapy after successful transplantation: a national survey. Kidney Int 1980;18:110-4.

56. Roussey-Kesler G, Giral M, Moreau A, et al. Clinical operational tolerance after kidney transplantation. Am J Transplant 2006;6:736-46.

57. Cai J, Lee J, Jankowska-Gan E, et al. Minor H antigen HA-1-specific regulator and effector CD8+ T cells, and HA-1 microchimerism, in allograft tolerance. J Exp Med 2004;199:1017-23.

58. Alexander SI, Smith N, Hu M, et al. Chimerism and tolerance in a recipient of a deceased-donor liver transplant. N Engl J Med 2008;358:369-74.

59. Larsen CP, Knechtle SJ, Adams A, Pearson T, Kirk AD. A new look at blockade of T-cell costimulation: a therapeutic strategy for long-term maintenance immunosuppression. Am J Transplant 2006;6:876-83.

60. Lechler RI, Sykes M, Thomson AW, Turka LA. Organ transplantation-how much of the promise has been realized? Nat Med 2005;11:605-13.

61. Kirk AD, Hale DA, Mannon RB, et al. Results from a human renal allograft tolerance trial evaluating the humanized CD52-specific monoclonal antibody alemtuzumab (CAMPATH-1H). Transplantation 2003;76:120-9.

62. Kirk AD, Mannon RB, Kleiner DE, et al. Results from a human renal allograft tolerance trial evaluating T-cell depletion with alemtuzumab combined with deoxyspergualin. Transplantation 2005;80:1051-9.

63. Starzl TE, Murase N, Abu-Elmagd K, et al. Tolerogenic immunosuppression for organ transplantation. Lancet 2003;361:1502-10.

64. Pree I, Pilat N, Wekerle T. Bone marrow transplantation as a strategy for tolerance induction in the clinic. Front Biosci 2009;14:611-20.

65. Gandy KL, Weissman IL. Tolerance of allogeneic heart grafts in mice simultaneously reconstituted with purified allogeneic hematopoietic stem cells. Transplantation 1998;65:295-304.

66. Slavin S, Fuks Z, Kaplan HS, Strober S. Transplantation of allogeneic bone marrow without graft-versus-host disease using total lymphoid irradiation. J Exp Med 1978;147:963-72.

67. Slavin S, Reitz B, Bieber CP, Kaplan HS, Strober S. Transplantation tolerance in adult rats using total lymphoid irradiation: permanent survival of skin, heart, and marrow allografts. J Exp Med 1978;147:700-7.

68. Slavin S, Strober S, Fuks Z, Kaplan HS. Induction of specific tissue transplantation tolerance using fractionated total lymphoid irradiation in adult mice: long-term survival of allogeneic bone marrow and skin grafts. J Exp Med 1977;146:34-48.

69. Lan F, Zeng D, Higuchi M, Higgins JP, Strober S. Host conditioning with total lymphoid irradiation and antithymocyte globulin prevents graft-versus-host disease: the role of CD1-reactive natural killer T cells. Biol Blood Marrow Transplant 2003;9:355-63.

70. Strober S, Modry DL, Hoppe RT, et al. Induction of specific unresponsiveness to heart allografts in mongrel dogs treated with total lymphoid irradiation and antithymocyte globulin. J Immunol 1984;132:1013-8.

71. Strober S, Dhillon M, Schubert M, et al. Acquired immune tolerance to cadaveric renal allografts. A study of three patients treated with total lymphoid irradiation. N Engl J Med 1989;321:28-33.

72. Strober S, Lowsky RJ, Shizuru JA, Scandling JD, Millan MT. Approaches to transplantation tolerance in humans. Transplantation 2004;77:932-6. 
73. Scandling JD, Busque S, Dejbakhsh-Jones S, et al. Tolerance and chimerism after renal and hematopoietic-cell transplantation. N Engl J Med 2008;358:362-8.

74. Ildstad ST, Sachs DH. Reconstitution with syngeneic plus allogeneic or xenogeneic bone marrow leads to specific acceptance of allografts or xenografts. Nature 1984;307:168-70.

75. Sachs DH, Sykes M, Kawai T, Cosimi AB. Immuno-intervention for the induction of transplantation tolerance through mixed chimerism. Semin Immunol 2011;23:165-73.

76. Guzzetta PC, Sundt TM, Suzuki T, et al. Induction of kidney transplantation tolerance across major histocompatibility complex barriers by bone marrow transplantation in miniature swine. Transplantation 1991;51:862-6.

77. Kawai T, Cosimi AB, Colvin RB, et al. Mixed allogeneic chimerism and renal allograft tolerance in cynomolgus monkeys. Transplantation 1995;59:256-62.

78. Kimikawa M, Kawai T, Sachs DH, et al. Mixed chimerism and transplantation tolerance induced by a nonlethal preparative regimen in cynomolgus monkeys. Transplant Proc 1997;29:1218.

79. Huang CA, Fuchimoto Y, Scheier-Dolberg R, et al. Stable mixed chimerism and tolerance using a nonmyeloablative preparative regimen in a large-animal model. J Clin Invest 2000;105:173-81.

80. Spitzer TR, Delmonico F, Tolkoff-Rubin N, et al. Combined histocompatibility leukocyte antigen-matched donor bone marrow and renal transplantation for multiple myeloma with end stage renal disease: the induction of allograft tolerance through mixed lymphohematopoietic chimerism. Transplantation 1999;68:480-4.

81. Cosimi AB, Sachs DH. Mixed chimerism and transplantation tolerance. Transplantation 2004;77:943-6.

82. Fudaba Y, Spitzer TR, Shaffer J, et al. Myeloma responses and tolerance following combined kidney and nonmyeloablative marrow transplantation: in vivo and in vitro analyses. Am J Transplant 2006;6:2121-33.

83. Kawai T, Cosimi AB, Spitzer TR, et al. HLA-mismatched renal transplantation without maintenance immunosuppression. N Engl J Med 2008;358:353-61.

84. Akashi K, Traver D, Miyamoto T, Weissman IL. A clonogenic common myeloid progenitor that gives rise to all myeloid lineages. Nature 2000;404:193-7.

85. Manz MG, Miyamoto T, Akashi K, Weissman IL. Prospective isolation of human clonogenic common myeloid progenitors. Proc Natl Acad Sci USA 2002;99:11872-7.
86. BitMansour A, Burns SM, Traver D, et al. Myeloid progenitors protect against invasive aspergillosis and Pseudomonas aeruginosa infection following hematopoietic stem cell transplantation. Blood 2002;100:4660-7.

87. Arber C, Bitmansour A, Shashidhar S, et al. Protection against lethal Aspergillus fumigatus infection in mice by allogeneic myeloid progenitors is not major histocompatibility complex restricted. J Infect Dis 2005; 192:1666-71.

88. Domen J, Sun L, Trapp K, et al. Tolerance induction by hematopoietic cell transplantation: combined use of stem cells and progenitor cells. J Heart Lung Transplant 2011;30:507-14.

89. Dvorak CC, Wright NB, Wong WB, et al. Safety of hematopoietic stem cell transplantation in children less than three years of age. Pediatr Hematol Oncol 2008;25:705-22.

90. Gandy KL, Domen J, Aguila H, Weissman IL. CD8+TCR+ and CD8+TCRcells in whole bone marrow facilitate the engraftment of hematopoietic stem cells across allogeneic barriers. Immunity 1999;11:579-90.

91. Colson YL, Shinde Patil VR, Ildstad ST. Facilitating cells: novel promoters of stem cell alloengraftment and donor-specific transplantation tolerance in the absence of GVHD. Crit Rev Oncol Hematol 2007;61:26-43.

92. BitMansour A, Cao TM, Chao S, Shashidhar S, Brown JM. Single infusion of myeloid progenitors reduces death from Aspergillus fumigatus following chemotherapy-induced neutropenia. Blood 2005;105:3535-7.

93. Domen J, Weissman IL. Hematopoietic stem cells need two signals to prevent apoptosis; BCL-2 can provide one of these, Kitl/c-Kit signaling the other. J Exp Med 2000;192:1707-8.

94. Czechowicz A, Kraft D, Weissman IL, Bhattacharya D. Efficient transplantation via antibody-based clearance of hematopoietic stem cell niches. Science 2007;318:1296-9.

95. Dillman RO. Cancer immunotherapy. Cancer Biother Radiopharm 2011;26:1-64

96. Weissenbacher A, Boesmueller C, Brandacher G, et al. Alemtuzumab in solid organ transplantation and in composite tissue allotransplantation. Immunotherapy 2010;2:783-90.

97. Nishikawa S, Kusakabe M, Yoshinaga K, et al. In utero manipulation of coat color formation by a monoclonal anti-c-kit antibody: two distinct waves of c-kit-dependency during melanocyte development. EMBO J 1991;10:2111-8.

98. Yoshinaga K, Nishikawa S, Ogawa M, et al. Role of c-kit in mouse spermatogenesis: identification of spermatogonia as a specific site of c-kit expression and function. Development 1991;113:689-99. 